\title{
Keberhasilan inseminasi buatan menggunakan semen sexing beku pada Sapi Persilangan Ongole
}

\section{The success rate of artificial insemination by using frozen sexing semen in Ongole Cross Breed Cow}

\author{
Dwi Susan Setiyani *, Aulia Puspita Anugra Yekti, Kuswati, dan Trinil Susilawati* \\ Fakultas Peternakan Universitas Brawijaya \\ Jalan Veteran Malang 65145 Jawa Timur
}

Submitted: 03 Juli 2018, Accepted: 07 Desember 2018

\begin{abstract}
ABSTRAK: Hasil IB pada sapi Potong diharapkan menghasilkan anak jantan karena mempunyai pertambahan berat badan yang cepat, sehingga didalam penelitian ini dilakukan IB menggunakan semen hasil sexing dengan metode sentrifugasi gradien densitas percoll yang mengandung sperma $\mathrm{Y}$. Penelitian ini dilakukan untuk mengetahui dan mengevaluasi tingkat keberhasilan Inseminasi Buatan (IB) menggunakan semen sexing beku pada sapi Persilangan Ongole. Metode yang digunakan dalam penelitian ini adalah penelitian eksperimental lapangdengan dua perlakuan yaitu IB semen sexing beku (P1) dan P2 semen non sexing beku (P2) pada 54 ekor sapi betina Persilangan Ongole. Variabel yang diamati adalah nilai Non Return Rate ${ }_{1}\left(\mathrm{NRR}_{1}\right)$, Non Return Rate ${ }_{2}\left(\mathrm{NRR}_{2}\right)$ dan Conception Rate $(\mathrm{CR})$. Hasil penelitian menunjukkan bahwa tingkat keberhasilan IB pada sapi Persilangan Ongole berdasarkan nilai $\mathrm{NRR}_{1}$ dan $\mathrm{NRR}_{2}$ semen sexing beku lebih rendah daripada semen non sexing beku dengan nilai $\mathrm{NRR}_{1}$ berturut-turut adalah $73,91 \%$; $93,54 \%$ sedangkan nilai $\mathrm{NRR}_{2}$ berturut-turut adalah $69,56 \% ; 83,87 \%$. Berdasarkan hasil analisa deskriptif nilai CR semen sexing beku lebih tinggi daripada semen non sexing beku yang ditunjukkkan dengan nilai CR semen sexing beku dan semen non sexing beku adalah $43,47 \% ; 35,48 \%$.
\end{abstract}

Kata kunci : Non Return Rate; Conception Rate; Semen Sexing

ABSTRACT: The Artificial Insemination (AI) results in Beef cattle are expected to be male calf because they can increaseweight gain rapidly, so in this study AI was carried out by using sexing semen with Percoll density gradient centrifugation method containing Y sperm. This study was conducted to evaluate the success rate of AI using frozen sexing semen on Ongole Cross Breed. The study method used wasexperimental, comparing AI frozen sexing semen and frozen semen in 54 Ongole Cross Breed. The study variableswere Non Return Rate ${ }_{1}\left(\mathrm{NRR}_{1}\right)$, Non Return Rate ${ }_{2}\left(\mathrm{NRR}_{2}\right)$ and Conception Rate (CR).The study showed that the success rate of based on the value of $\mathrm{NRR}_{1}$ and $\mathrm{NRR}_{2} \mathrm{AI}$ using frozen sexing semen on Ongole Cross Breed is lower than un sexed frozen semen with the $\mathrm{NRR}_{1}$ value is $73,91 \%$; $93,54 \%$ while the value of $\mathrm{NRR}_{2}$ was $69,56 \%$; $83,87 \%$. Based on CR value of frozen sexing semen higher than un sexed frozen semen showed CR valuewas $43,47 \% ; 35,48 \%$.

Keywords: Non Return Rate; Conception Rate; Semen Sexing.

*Corresponding Author: dwisusan94@gmail.com and trinil_susilawati@yahoo.com

DOI: 10.21776/ub.jiip.2018.028.03.09 


\section{PENDAHULUAN}

Sapi potong adalah salah satu ternak ruminansia yang menjadi penyumbang pasokan daging terbesar di Indonesia (Suryana, 2009). Badan Pusat Statistik (2016) menyatakan bahwa angka produksi daging dari tahun 2009 mencapai 107.768 ton hingga tahun 2016 mengalami penurunan secara berangsur-angsur hingga mencapai 97.675ton di Jawa Timur. Permintaan daging yang masih kurang dipenuhi dari penerimaan daging impor dan sapi bakalan (Yulyanto, Susilawati dan Ihsan, 2016). Keadaan ini memerlukan perhatian khusus sehingga dapat mengalami perbaikan pasokan daging dan memenuhi permintaan masyarakat.

Inseminasi Buatan (IB) merupakan program yang dapat dilakukan untuk meningkatkan produktivitas daging dan mutu genetik (Yimer et al., 2014). Salah satu bahan yang perlu dipersiapkan dalam pelaksanaan IB adalah semen yang digunakan. Bioteknologi bidang reproduksi mengalami perkembangan dalam program IB melalui penggunaan semen hasil proses pemisahan kromosom $\mathrm{X}$ dan $\mathrm{Y}$ atau semen sexing pada pelaksanaan IB. Cooke et al. (2014) menyatakan terjadi peningkatan angka kebuntingan dengan menggunakan semen hasil sexing dan krioperservasi. Hal ini mendukung untuk dilaksanakannya program IB menggunakan semen sexing. Pemanfaatan spermatozoa $\mathrm{X}$ dan $\mathrm{Y}$ diyakini meningkatkan efisiensi program IB dalam usaha peternakan (Fernanda, Susilawati dan Isnaini, 2015). Sexing spermatozoa dengan menggunakan metode sentrifugasi Gradien Densitas Percoll dapat memisahkan spermatozoa X dan Y sebesar 89\% (Susilawati, 2014) Metode ini yang digunakan di BBIB Singosari Malang.

Penilaian reproduksi sapi hasil IB dapat dilakukan dengan melihat parameter Non Return Rate (NRR) dan Conception Rate (CR) (Rosita, Susilawati dan Wahjun- ingsih, 2015). Penelitian ini bertujuan untuk mengetahui dan mengevaluasi pelaksanaan IB menggunakan semen sexing beku pada sapi Persilangan Ongole di peternakan rakyat yang tersebar di Kecamatan Palang, Kabupaten Tuban.

\section{MATERI DAN METODE}

Penelitian ini dilaksanakan pada tanggal 23 Juli 2017 - 5 November 2017 di beberapa desa yakni Desa Cepokorejo, Desa Cendoro, Desa Gesikharjo, Desa Glodok, Desa Ketambul, Desa Leran Wetan, Desa Leran Kulon, Desa Ngimbang dan Desa Wangun di Kecamatan Palang, Kabupaten Tuban.

Materi yang digunakan dalam penelitian ini adalah 54 ekor sapi betina Persilangan Ongole dengan memliki tandatanda birahi yang cukup jelas yaitu vulva kemerahan, bengkak dan berlendir. Pemberian pakan konsentrat sebagai pakan tambahan adalah sebanyak $3 \mathrm{~kg} / \mathrm{ekor} / \mathrm{hari}$ selama 3 hari kepada seluruh akseptor IB, sedangkan penginjeksian vitamin sebanyak $10 \mathrm{~mL}$ dilakukan pada akseptor IB menggunakan semen sexing beku. Metode yang digunakan dalam penelitian ini adalah eksperimental lapang dengan membandingkan hasil IB semen sexing beku (P1) dan semen non sexing beku (P2). Data yang diambil merupakan data primer yang diperoleh melalui pengamatan secara langsung dan wawancara terhadap peternak maupun inseminator. Variabel yang diamati pada penelitian ini terdiri dari yakni Non Return Rate ${ }_{1}\left(\mathrm{NRR}_{1}\right)$, Non Return Rate $_{2}\left(\mathrm{NRR}_{2}\right)$ dan Conception Rate (CR). Data yang diperoleh dianalisa secara deskriptif.

Non Return Rate (NRR) adalah persentase ternak betina yang tidak mengalami berahi lagi dalam waktu satu siklus NRR 1 (antara 19- 22 hari) dan NRR 2 (antara 4143) Menurut Susilawati (2013) , Pada NRR 1 dan NRR2 perhitungan NRR:

$$
N R R=\frac{\text { Jumlah sapi di IB }- \text { Jumlah sapi di IB ulang }}{\text { Jumlah sapi di IB }}
$$


Conception Rate (CR) adalah persentase jumlah sapi betina yang bunting pada IB pertama. Menurut Feradis (2010), perhitungan CR:

\section{$C R=\underline{\text { Jumlah bunting IB ke-1 }}$ Jumlah akseptor}

HASIL DAN PEMBAHASAN Evaluasi Keberhasilan IB dengan Non Return Rate (NRR)

Pengamatan $\mathrm{NRR}_{1}$ dilakukan pada hari ke-19, 20 dan 21 setelah IB, sedangkan $\mathrm{NRR}_{2}$ dilakukan hari ke 41, 42 dan 43 setelah IB. Hasil pengamatan $\mathrm{NRR}_{1}$ ddan $\mathrm{NRR}_{2}$ dapat dilihat pada Gambar 1.

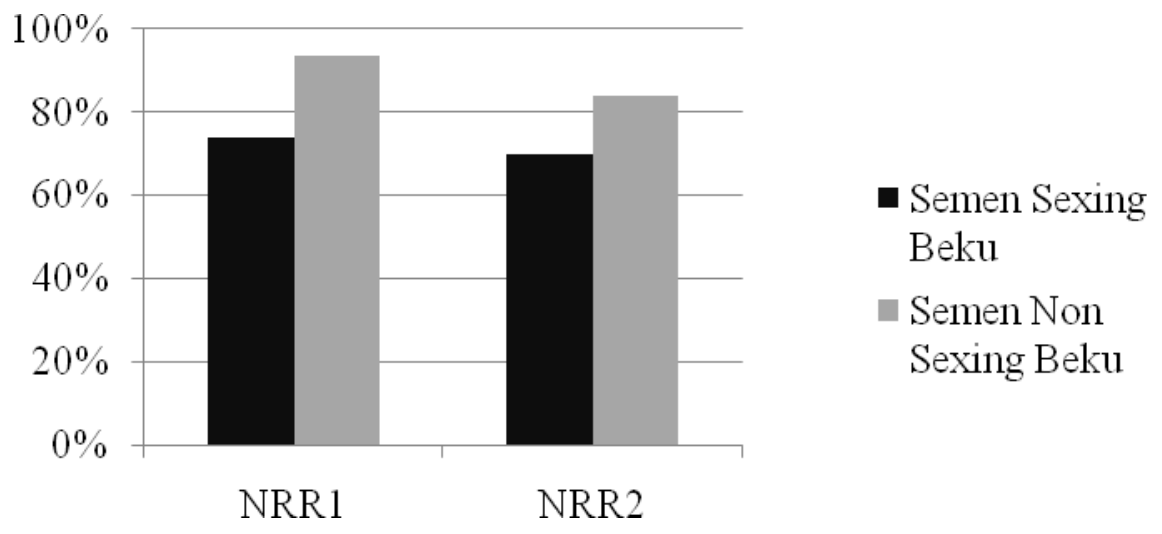

Gambar 1. Nilai $\mathrm{NRR}_{1}$ dan $\mathrm{NRR}_{2}$ pada Sapi Persilangan Ongole

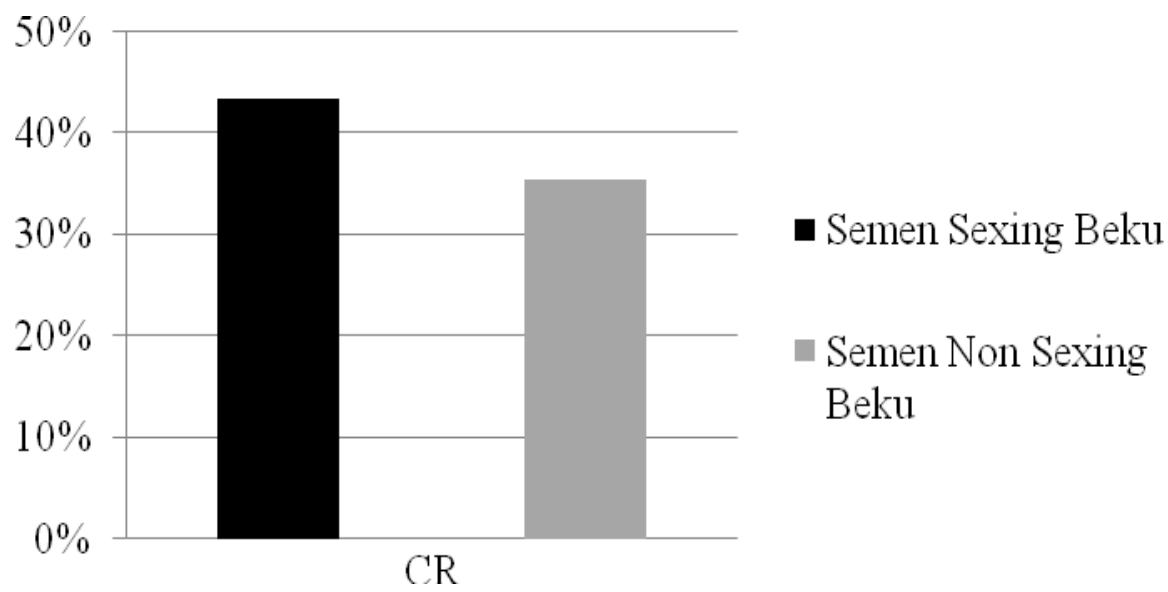

Gambar 2. Nilai Conception Rate (CR) pada Sapi Persilangan Ongole

Non Return Rate (NRR merupakan ukuran kesuburan ternak dan salah satu evaluasi konerja reproduksi dengan cepat tanpa menunggu kelahiran atau peristiwa partus (Varotto et al., 2016). Hasil NRR1 dan NRR2 hasil IB menggunakan semen beku sexing lebih rendah dari pada semen beku non sexing yaitu pada NRR 1 adalah $73,91 \%$ dan 93,54\%. Sedangkan NRR 2 adalah $69,56 \%$ dan $83,87 \%$. Hal ini dapat dilihat pada gambar 1 . Rendahnya keberhasilan fertilisasi disebabkan oleh kualitas semen sexing lebih rendah dari pada semen non sexing, karena terjadi kerusakan membran spermatozoa setelah sexing (Susilawati, 2014). Sedangkan terjadinya penurunan nilai NRR 1 ke NRR2 adalah karena terjadinya silent Heat atau kematian embrio, menurut pendapat Yekti dkk. 
(2017) bahwa kandungan nutrisi yang tidak terpenuhi dapat menyebabkan gangguan reproduksi ternak berupa silent Heat atau Kematian embrio dini. Selain itu BCS yang rendah akan mempengaruhi penampakan birahi ternak. Anisa, Ondho dan Samsudewa (2017) menyatakan bahwa BCS yang berbeda pada ternak akan mempengaruhi kualitas tampilan birahi yang disampaikan ternak.

Nilai $\mathrm{NRR}_{1}$ maupun $\mathrm{NRR}_{2}$ memiliki besar antara $70 \%-90 \%$. Hal ini berarti nilai $\mathrm{NRR}_{1}$ dan $\mathrm{NRR}_{2}$ sudah optimal atau baik. Hal ini sesuai dengan pendapat Inas et al. (2017) menyatakan bahwa NRR pada sapi yang di IB mencapai $88,33 \%$, sedangkan pada penelitian Tas et al. (2007) menyatakan bahwa NRR pada sapi memiliki range $66,7 \%-79,9 \%$.

Pada penelitian ini terdapat peristiwa penurunan $\mathrm{NRR}_{1}$ menuju $\mathrm{NRR}_{2}$. Penurunan nilai NRR di lokasi penelitian ini diduga disebabkan oleh peristiwa kematian embrio di dalam tubuh ternak. Salah satu penyebab terjadinya kematian embrio ini adalah adanya gangguan dari ektoparasit dan endoparasit yang mengakibatkan stres pada akseptor IB. Hal ini sesuai dengan pendapat Susilawati (2011) yang menyatakan bahwa kematian embrio dapat terjadi akibat ternak tersebut mengalami gangguan reproduksi yang disebabkan oleh stres dengan adanya ektoparasit maupun endoparasit di sekitar ternak tersebut.

\section{Evaluasi Keberhasilan IB dengan Con- ception Rate (CR)}

Hasil pengamatan kebuntingan dapat dilihat pada Gambar 2. Nilai CR sapi Persilangan Ongole IB semen sexing beku dan semen non sexing beku berturut-turut adalah $43,47 \%$ dan $35,58 \%$. Nilai ini berbeda antara NRR dan CR yaitu hasil IB menggunakan semen beku sexing lebih tinggi dari pada non sexing. Keberhasilan IB selain dipengaruhi oleh kualitas semennya juga dipengaruhi oleh kondisi fisi- ologi induk dan ketepatan didalam melakukan IB, sehingga turunnya nilai NRR menjadi CR yang menjadikan perbedaan nilai disebabkan kondisi induknya, karena sangat bervariasinya kondisi sapi yang ada di lapang karena sistem pemeliharaannya yang tidak seragam.

Conception rate merupakan persentase kebuntingan pada hasil inseminasi pertama (Fernanda dkk., 2015). Nilai CR sapi Persilangan Ongole IB semen sexing beku dan semen non sexing beku dapat dikatakan masih rendah atau belum optimal. Hal ini sesuai dengan pendapat Boro et al. (2016) yang menyatakan bahwa angka konsepsi menggunakan semen sexing mencapai $45 \%$ dan Fanani, Subagyo dan Lutojo (2013) yang menyatakan bahwa standart CR pada sapi 60\%-70\%. Hal ini menunjukkan bahwa nilai CR sapi Persilangan Ongole belum optimal. Hal ini sesuai dengan pendapat Yekti dkk. (2017) yang menyatakan bahwa malnutrisi atau kekurangan nutrisi dapat mengakibatkan angka kebuntingan yang rendah. Kondisi BCS yang rendah diindikasikan ternak akan kekurangan nutrisi, sehingga berdampak negatif pada efisiensi reproduksi. Hal ini sesuai dengan pendapat Susilawati (2011) yang menyatakan bahwa ternak yang memiliki BCS terlalu kurus akan mengalami kesulitan dalam bereproduksi.

\section{KESIMPULAN}

Tingkat keberhasilan IB pada sapi Persilangan Ongole berdasarkan nilai $\mathrm{NRR}_{1}$ dan $\mathrm{NRR}_{2}$ semen sexing beku lebih rendah daripada semen non sexing beku sedangkan berdasarkan nilai $\mathrm{CR}$ semen sexing beku lebih tinggi daripada semen non sexingbeku.

\section{DAFTAR PUSTAKA}

Anisa, E., Y. S. Ondho., dan D. Samsudewa. 2017. Pengaruh body condition score (BCS) berbeda terhadap intensitas birahi sapi induk Simmental Peranakan Ongole (simpo).Jurnal 
Sain Peternakan Indonesia, 14(3):98106.

Badan Pusat Statistik. 2016. Statistik Populasi Ternak (ekor), 2009-2016. Diakses November 11, 2017, dari Dinas Peternakan Provinsi Jawa Timur. Dinas Peternakan Propinsi Jawa Timur.

Boro, P., B. C. Naha., A. Madkar and C. Prakash. 2016. Sexing of semen in bulls: a mini review. International Journal of Applied Research, 2(4): 460-462.

Cooke, R. F., D. W. Bohnert., B. I. Cappellozza., R. S. Marques., T. Delcurto and C. J. Mueller. 2014. Incorporation of sexed semen into reproductive management of cow-calf operations. Livestock Science, 163:165-171.

Fanani, S., Y. B. P. Subagyo dan Lutojo. 2013. Kinerja reproduksi Sapi Perah Peranakan Friesian Holstein (PFH) di Kecamatan Pudak, Kabupaten Ponorogo. Tropical Animal Husbandry, 2(1), 21-27.

Feradis. 2010. Bioteknologi Reproduksi pada Ternak. Bandung: Alfabeta.

Fernanda, M. T., T. Susilawati dan N. Isnaini. 2015. Keberhasilan ib menggunakan semen beku hasil sexing dengan metodesentrifugasi gradien densitas percoll (SGDP) pada Sapi Peranakan Ongole (PO). Jurnal IlmuIlmu Peternakan, 24(3): 1-8.

Inas, T. U., S. Endang., M. S. Pantja., S. T. Utomo and S. Pudji. 2017. Influence of ph vaginal mucosa when artifial insemination of non return rate (NRR) and conception rate (CR) on dairy cow in Ksu Tunas Setia Baru Pasuruan East Java. International
Journal of Development Research, 7(9) : 15540-15542.

Rosita, E. A., T. Susilawati dan S. Wahjuningsih. 2014. Keberhasilan ib menggunakan semen beku hasil sexing dengan metode sedimentasi putih telur pada Sapi PO Cross. Jurnal Ilmu-Ilmu Peternakan, 24(1):72-76.

Suryana. 2009. Pengembangan usaha ternak sapi potong berorientasi agribisnis dengan pola kemitraan. Jurnal Litbang Pertanian, 28(1):29-37.

Susilawati, T. 2011. Tingkat keberhasilan inseminasi buatan dengan kualitas dan deposisi semen yang berbeda pada Sapi Peranakan Ongole.Jurnal Ternak Tropika, 12(2), 15-24.

Susilawati,T. 2013. Inseminasi Buatan Pada Ternak. Malang : UB Press

Susilawati,T.2014. Sexing Spermatozoa. Malang : UB Press

Tas, M., S. S. Bacinoglu., U. Cirit., O. B. Ozdas and A. K. Kemal. 2007. Relationship between bovine fertility and the number of spermatozoa penetrating the cervical mucus within straws. Animal Reproduction Science, 101 : 18-27.

Varotto, A., R. Finocchiaro., J. Kaam., M. Marusi and M. Cassandro. 2016. Analysis of non return rate in Italian Holstein Friesien Bulls. Acta Agriiculturue Slovenica, 5:94-98.

Yekti, P. A.Y., T. Susilawati., M. N. Ihsan dan S. Wahjuningsih. 2017. Fisiologi Reproduksi Ternak (Dasar Manajemen Reproduksi). Malang : UB Press. 
Yimer, N., A. H. Noraisyah., Y. Rosnina., H. Wahid., K. Saisaifi and A. M. Hafizal. 2014. Comparison of cryopreservative effect of different levels of omega-3 egg-yolk in citrate extender on the quality of goat spermatozoa. Pakistan Veterinary Journal, 34(3) : 347-350.
Yulyanto, C. A., T. Susilawati dan M. N. Ihsan. 2016. Penampilan reproduksi Sapi Peranakan Ongole (PO) dan Sapi Peranakan Limousin di Kecamatan Sawoo Kabupaten Trenggalek. Jurnal Ilmu-Ilmu Peternakan, 24(2) : 49-57 